\title{
Information model for choosing a design solution for providing construction with mortar
}

\author{
Vadim Kabanov* \\ The National Research University "Moscow State University of Civil Engineering", 129337, \\ Moscow, Russia
}

\begin{abstract}
Building materials are usually classified according to the criterion of the possibility of creating a stock at the construction site. Mortars and concrete mixtures have a limited time during which they must be used in the construction of building structures. There are technologies for the use of dry components of mortars from which the mixture is prepared at the construction site. However, the technology of manufacturing mortars at specialized plants is widely used, followed by transportation of the finished cement-sand mixture to the construction site. The problem under consideration raises issues related to the volume of supply of mortars and the intensity of this building material consumption. Within the framework of the research, the tasks of analytical description of the construction and installation work intensity influence on the technological processes of cement-sand mortars delivery to the construction site have been solved, a block diagram of the selection of an economically feasible design solution for providing the production process with a building mixture has been developed. On the basis of the presented results in the form of mathematical dependencies and a block diagram, the conclusions about the influence of a design solution for providing construction with a cement-sand mixture on the duration and construction and installation work cost have been formulated. A graphic representation of the procedure for making a decision on the supply of a construction with a cement-sand mixture is supposed to be used for the development of software that provides a description of the construction processes functioning in space and time, including for 3D models.
\end{abstract}

\section{Introduction}

An information model, for the purposes of this publication, is information describing the position of a simulated object in space and time. It is known that the processes of buildings and structures erection represent the production technological processes movement of the construction and installation works around the capital construction object. The current state of technological processes or, as it is customary to call the "front of work" is the subject of information modeling.

* Corresponding author: kabanovvn@yandex.ru 
Space in this work is represented by the coordinates describing the position of one or more points in three-dimensional space. Obviously, to describe the position of a point in space, it is necessary to determine the position of the origin of coordinates relative to which, according to the rules of analytical geometry, the positions of points, segments, planes are calculated.

Time is represented as the construction duration. For the initial period of time, the beginning of work on the capital construction facility construction is taken. The number of technological processes that can simultaneously operate at the construction site is determined by the work schedule. The work schedule is developed according to the rules for constructing a Gantt chart, cyclogram or using the methods provided by the graph theory (for building network construction models).

In most cases, the work schedule is a model describing the main construction technological processes. That is, the processes usually used for the construction of parts of buildings and structures. Secondary processes supporting the main construction processes are designed separately or not developed at all. At the same time, the design solutions for the secondary construction processes development can have a significant impact on both the construction speed and the formation of the finished construction products' cost. One of these key processes is the provision of construction of buildings and structures with mortar.

Traditionally, mortar is most used when performing work on the construction of structures made of small-piece materials (brickwork). The published research results focus on measuring the speed of work [1], developing flexible robotic industries [2, 3], technological processes automation using building solutions $[4,5]$. If we exclude the publications that describe the improvement of technological processes for the production of artificial small-piece materials by firing (brick) or natural hardening (based on mineral binders), then it is logical to dwell on the methods of providing the building and construction processes with mortar.

With all the importance of determining the optimal duration of mixing in the preparation of mortars $[6,7,8]$, in this work, the indicator of the mortar unit volume cost is used as a criterion for choosing a design solution. It should be emphasized that the prospects for improving the processes of preparing cement-sand mortars at a construction site are advisable to be associated with the use of a ready-made dry mix supplied in silos [9].

The issues of providing construction with materials, structures and products are most often considered within the framework of solving the logistics problems [10, 11]. However, one of the general drawbacks of the published research results is the lack of a relationship between the mortar consumption intensity and the volume of its supply per unit time to the place of construction and installation work. On this basis, the topic of this study should be classified as relevant.

\section{Purpose of work:}

to develop an information model describing the process of providing construction with cement-sand mortar. To achieve the stated goal, the following tasks were solved:

- the analytical and graphical dependence of the mortar cost value on the change in the consumption intensity was obtained;

- a block diagram for the development of a software product, which ensures the selection of the most cost-effective design solution, has been developed.

\section{Research methods}

When building an information model, the following assumptions were used: 
- the cost of preparing a unit volume of mortar at the construction site is constant $C_{D 1}=$ const;

- the cost of a unit volume of mortar, which is produced in a concrete plant, constant $C_{V 1}$ $=$ const;

- the duration of the mortar delivery from the concrete plant to the construction site is known and constant, $t=$ const;

- the cost of operating a car that provides mortar delivery to the construction site per hour, $C_{C}=$ const.

The mortar consumption rate was used as a variable in the information model, which depends, for example, on the number of bricklayers who work at the site, $v_{D}$, as well as the volume of mortar delivered to the construction site by one vehicle, $v_{S}$. The analytical relationship between the listed constant and variable values is an information model that describes the decision-making process on the choice of a method for providing the building erection process with mortar.

When constructing the mathematical apparatus of the information model, such wellknown procedures as mathematical logic, elementary algebra, and analytical geometry were used. The constructed mathematical model is the basis for a numerical experiment.

As a criterion for choosing a design solution for providing the construction process with mortar, the quantitative value of the cost of a unit volume of mortar used to perform construction and installation works is used. The use of an economic indicator for the choice of design solutions is possible provided that the standard requirements for mortar are met.

\section{Results}

An analytical record of the choice of a design solution according to the mortar cost criterion at the construction site does not require proof:

$$
C_{D 1}-C_{S 1}= \begin{cases}>0 & - \text { the mortar is brought to the construction site } \\ <0 & - \text { the mortar is prepared at the construction site }\end{cases}
$$

where $C_{D 1}$ determines the cost of preparing a unit volume of mortar at a construction site, which does not depend on the mortar consumption intensity (work intensity), $v_{D}$;

- $C_{S}$ is the cost of mortar, taking into account the delivery cost to the work place, which depends on the mortar consumption intensity per unit of time (work intensity), $v_{D}$.

An increase in the mortar production volume at the construction site to the required value of the mortar consumption intensity per unit of time is achieved as a result of attracting additional mixing plants. On this basis, it was concluded that the cost of the solution prepared at the construction site is constant.

The use of mortars, which are made on stationary concrete mixing plants at some distance from the construction site, requires additional computational procedures. Such procedures are necessary to determine the change in the mortar cost, for example, when delivered in vehicles with an incomplete load of the body. For these purposes, it is advisable to use the mathematical expression:

$$
C_{S 1}=\frac{v_{S} C_{V 1}+t C_{C}}{v_{S}}=C_{V 1}+\frac{t C_{C}}{v_{S}}
$$

where $C_{S 1}$ is the cost of a unit volume of mortar, taking into account the cost of transportation from the concrete plant to the construction site; 
$-C_{V 1}$ is the cost of preparing mortar in a concrete plant;

$-t$ is the duration of the technological cycle of the vehicle that delivers the mortar from the concrete plant to the construction site;

- $C_{C}$ is the cost of operating a car per unit of time (as a rule, per hour);

- $v_{S}$ is the volume of mortar transported by a car in one technological cycle.

If equation 2 is considered as the dependence of the mortar cost on the amount of volume transported by the car for 1 technological cycle, then $C_{S 1}=f\left(v_{S}\right)$ is a complex function, the graphical representation of which is a curved line. If the cost of preparing a unit volume of mortar at the construction site is constant and equal to $C_{D 1}$, then the correspondence $C_{D 1}=f\left(v_{D}\right)$ is a straight line parallel to the axis $v_{D}$.

Choosing a design solution for the dependencies $C_{S 1}=f\left(v_{S}\right)$ and $C_{D 1}=f\left(v_{D}\right)$ represents two areas. The first area corresponds to the values along the axis $v$ (values are measured on this axis $v_{S}$ and $v_{D}$ ), which lie to the left of the coordinate $v$, which corresponds to the intersection point of the graphs of the functions $C_{S 1}=f\left(v_{S}\right)$ and $C_{D 1}=f\left(v_{D}\right)$. The second area is defined by the points that lie to the right of the functions' graphs intersection point (Fig. 1). Cost selection is not defined at the intersection point $v=v_{S}=v_{D}$.

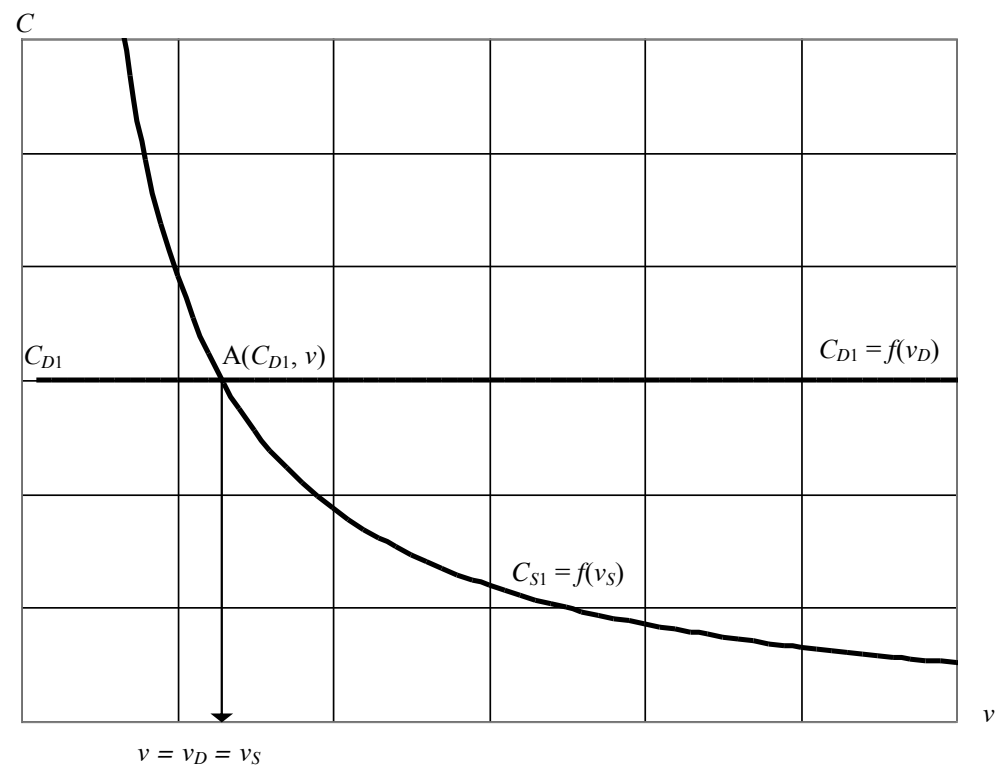

Fig 1. Graphical representation of the selection procedure on the information model ${ }^{1}$

Obviously, to find the point of intersection of the functions $C_{S 1}=f\left(v_{S}\right)$ and $C_{D 1}=f\left(v_{D}\right)$ it is necessary and sufficient to solve the system of equations 3 :

$$
\left\{\begin{array}{l}
C_{S 1}=f\left(v_{S}\right) \\
C_{D 1}=f\left(v_{D}\right)
\end{array}\right.
$$

The system of equations 3 is solved graphically (Fig. 1) or analytically. The analytical solution of the system of equations 3 is the equation 4:

\footnotetext{
${ }^{1}$ Designed by the author according to equation 3 .
} 


$$
v=\frac{t C_{C}}{C_{D 1}-C_{V 1}}
$$

The condition under which the system of equations 3 has a solution does not require proof: $C_{D 1}>C_{S 1}$. If the condition is not met, then the system equation 3 has no solution in the region of positive values. Intersection point of function graphs $C_{S 1}=f\left(v_{S}\right)$ and $C_{D 1}=$ $f\left(v_{D}\right)$ has the coordinates $\mathrm{A}\left(C_{D 1}, v\right)$, fig. 1. A graphic representation of the information model for choosing a design solution to ensure the erection processes of buildings and structures with mortar is shown in Fig. 1. However, to automate the design process and the design solutions selection, it is necessary to transfer the analytical solution to one of the programming languages. For this purpose, a block diagram is being developed for a detailed description of the information model operation in automatic mode (Fig. 2).

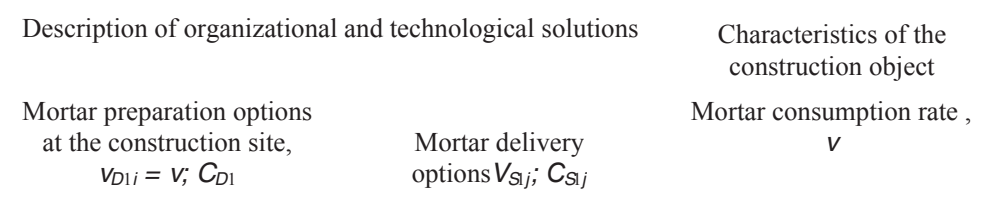

yes $\quad C_{D \downarrow i}>C_{V 1}+\frac{t C_{C j}}{v_{S j}} \quad$ no

no

yes

Development of working documentation for design solutions

Designing the process of preparing mortar at the construction site

Designing the delivery of mortar by vehicles

Fig 2. Block diagram of an automated system for making the design solutions for the preparation of mortars $^{2}$

It is quite obvious that several technological solutions can be used for the preparation of mortar on a construction site, which may differ in both technical and economic characteristics. In order to take this difference into account, an index is introduced in the block diagram (Fig. 2) «ii», which is designed to distinguish the technologies from each other. The mortar delivery cost depends on the technical characteristics of the vehicles, taken into account using the index $\langle j\rangle$.

${ }^{2}$ Designed by the author according to the rules established ISO 5807:1985 Information processing Documentation symbols and conventions for data, program and system flowcharts, program network charts and system resources charts. 


\section{Conclusion}

The above-described research results are the basis for the following conclusions:

1. The information model of the construction process (main or secondary) can be successfully used not only to describe the specific technologies for the construction of buildings and structures, but also to automate the process of choosing the design solutions. It is important to emphasize that the process automation of choosing the design solutions at the stage of developing working documentation in construction has a very significant impact on the duration and cost of construction and installation work.

2. An analytical description (equations 1 - 4) and a graphical representation of the procedure for choosing a design solution (Fig. 1) were obtained for the information model of providing the processes of buildings and structures erection with mortar. Thus, as a result of the research, not only the mathematical apparatus, which is used in the design solutions selection for the provision of construction with mortar has been developed, but also a visual display of possible results on the graphs have been obtained (Fig. 1).

3. The practical significance of the work lies in the fact that the theoretical development of the issue of automating design decision-making is implemented in a block diagram. It is important to emphasize that the block diagram (Fig. 2) significantly reduces labor costs when writing a program in one of the programming languages. A software product developed on the basis of a block diagram (Fig. 2) does not apply to the description of the main process of a building or structure erection. Since the process of providing mortar is more likely to be related to an auxiliary process, then the software product developed on the basis of the flowchart (Fig. 2) will also be more likely to be referred to as subroutines.

It should be noted that it is not possible to develop an information model of the construction process of a building or structure without a description of secondary processes. The depth of detail in the construction process development will determine the need for digital technologies in the capital construction projects construction.

\section{References}

1. M.W. Emsley, A.R. Duff, D. Zambetakis, CTB 90 Bulding economics and construction management 1(6) F161-F172.

2. B. Bley, F. Anliker, Automation and robotics in construction 11, 111-116 (1994).

3. J.P. Sousa, P.A. Varela, P.F. Martins, Between Manual and Robotic Approaches to Brick Construction in Architecture Expanding the Craft of Manual Bricklaying with the Help of Video Projection Techniques, (ECAADE 2015) Real time - extending the reach of computation 2, $361-370$ (2015).

4. A. Malkwitz, A.J. Spengler, T. Bruckmann, Investigation of robot systems in masonry construction. Bautechnik 96(5) 375 - 379.

5. T. Kranzler, A. Hannig, U. Meyer, New VDPM leaflet "Mauerwerk mit Dunnbettmortel", Mauerwerk 22(6) 356-362.

6. E. Tkach, K. Nurbaturov, MATEC Web of Conferences $\mathbf{1 1 7}$ an 00168, DOI: $10.1051 /$ matecconf $/ 201711700168$

7. P.N Hiremath, S.C. Yaragal, Construction and building materials 141, 271-288, DOI: 10.1016/j.conbuildmat.2017.03.009

8. K.P. Verian, S.R. Kowaleski, M.D. Carli, R.P. Bright, E. Maandi, G. Sill, Transportation research record $\mathbf{2 6 7 4}$ (2), $1-9$ (2020) DOI: 10.1177/0361198120905595 
9. F. Leopolder, ZKG international 64 (2), 30-48 (2011).

10. V. Albino, R.M. Dangelico, A.M. Petruzzelli, Establishing the foundation of collaborative networks 243, 657-666 (2007).

11. P. Boatwright, S. Borle, J.B. Kadane, Journal of the American statistical association 98 (463), 564-572 (2003), DOI: 10.1198/016214503000000404 